\title{
Report from the Faculty of Family Planning and Reproductive Health Care AGM, May 2001
}

\section{Organon Laboratories Award - Oral Presentation Award The occupational profile and associated training needs of the family planning nurse prescriber}

Claire Tyler, MSc, RGN, RSCN, Dip Nursing Studies, Advanced Nurse Practitioner, Central Family Planning Clinic, Norfolk and Norwich University Hospital NHS Trust

Correspondence: Claire Tyler, Central Family Planning Clinic, 2-4 Brunswick Road, Norwich, Norfolk NR2 2HA, UK

The Journal of Family Planning and Reproductive Health Care 2002: 28(1): 40-41

\begin{abstract}
Background
The issue of nurse prescribing is highly topical, with various UK Government directives recommending this extension to the nursing role. Yet there remains no agreement as to the occupational profile of the nurse prescriber and ongoing discussion as to the level and content of prerequisite educational programmes. This study as reported by Tyler and Hicks ${ }^{1}$ was an attempt to address these unresolved aspects with family planning nurses.
\end{abstract}

\section{Method}

A postal survey was adopted using a psychometrically valid and reliable training needs analysis questionnaire. The questionnaire was administered to the total population of family planning nurses in England and Wales who are currently registered members of the National Association of Nurses for Contraception and Sexual Health.

The training needs analysis questionnaire required respondents to assess 40 core clinical tasks according to three rating criteria: how critical each task was both to their current role as family planning nurses, and to the role of the family planning nurse prescriber, and how well each was performed. Comparisons of the ratings provided an indicative profile of the role of the family planning nurse prescriber and a prioritised list of training needs to achieve this status. Of the 1142 questionnaires distributed, 388 were returned.

\section{Results}

Significant interest was reported by the sample in becoming nurse prescribers. The family planning nurse prescriber's role was generally defined in terms of prescribing functions. However, from the 15 top-rated skills of the family planning nurse prescriber, it is clear that the role is not seen exclusively in terms of prescribing.

\section{Conclusions}

The top-rated skills of the family planning nurse prescriber fit competencies outlined for advanced nursing practice, reinforcing the argument that the role of the nurse prescriber is commensurate and compatible with that of the nurse practitioner.

This study offers timely empirical evidence to the current debate about the occupational boundaries of the nurse prescriber, and the level and content of education required for this role. Its findings are consistent with other training needs analyses that have focused on educational requirements for advanced nursing practice, and accord with policy documents on the traditional nursing role.

In May 2001, the Government confirmed that independent nurse prescribing will be extended into the area of health promotion, identifying family planning nurses among those suitable for training. The findings of this study are compatible with their recommendations that nurses with additional qualifications, e.g. specialist practitioners, clinical nurse specialists in relevant areas, nurse consultants and nurse practitioners should be priority nominees for training.

Within family planning, many services currently widely use patient group directions as a means of nurses supplying prescription-only medicines. While future independent nurse prescribing within family planning may be a natural progression, it remains important that outside the specialty experiences and research are shared.

\section{Publication of the full article}

The full paper by Claire Tyler was published in the September 2001 issue of the Journal of Advanced Nursing.

\footnotetext{
Reference
1 Tyler $\mathrm{C}$, Hicks C. The occupational profile and associated training needs of the nurse prescriber: an empirical study of family planning nurses. J Adv Nurs 2001; 35 (5): 644-653.

Further reading

Castledine G, McGee P. Advanced and specialist nursing practice. Oxford: Blackwell Sciences,

1998.
Ford P, Walsh M. New rituals for old: nursing through the looking glass. Oxford: Butterworth Heinemann, 1994

Hicks C, Hennessy D, Barwell F. Development of a psychometrically valid training need analysis instrument for use with primary health care teams. Health Serv Man Res 1996; 9
} 